\title{
El desencantamiento de la Escuela: sus cambios y zarandeos en la era posindustrial
}

\author{
Carlos Enrique Mosquera Mosquera \\ Jorge Enrique Ramírez Martínez ${ }^{2}$
}

Recibido: 14-08-2019

Aceptado: 16-10-2019

\section{Resumen}

El presente artículo pretende reflexionar sobre los zarandeos y cambios que experimenta la escuela en la era posindustrial a través de dos categorías: 1) el desencantamiento de la escuela y su desinstitucionalización, y 2) la civilidad: una conquista a través de la estructura de la socialización. En este se propone que, frente a la caoticidad, la desinstitucionalización y la dispersión generalizada de la escuela, así como frente a la subjetividad en la era posmoderna, se posibilite desde los procesos educativos un diálogo entre algunas estructuras del pasado y del presente, para que el proceso de licuefacción no sea tan veloz y nos arrastre a la pérdida de sentido del mundo y de la vida. También se propone retomar la estructura social de la escuela para formar una civilidad

1. Docente e investigador de la Institución Universitaria Marco Fidel Suárez (Antioquia). Facultad de Educación y Facultad de Ciencias Empresariales. Integrantes de los grupos de investigaciones SIT-MARCO de la misma universidad, y Educación y Desarrollo de la Universidad Cooperativa de Colombia. Licenciado en Filosofía de la Universidad Católica de Oriente (UCO); Magíster en Educación de la Universidad Santo Tomás (USTA); doctorando en Educación de la Universidad Nacional de Rosario (UNR). Trabaja en las líneas de investigaciones de Prácticas pedagógicas contemporáneas y memoria y conflicto armado.

Correo electrónico: carlosfilosofo@hotmail.com

ORCID: http://orcid.org/0000-0002-4806-3145

Google Scholar: https://scholar.google.es/citations?user=09bHzekAAAAJ\&hl=es

2. Ex-coordinador del Centro de Investigación VUAD (Bogotá). Facultad de Educación y Facultad de Ciencias y Tecnologías de la Universidad Santo Tomás: Licenciado en Física y Magíster en Educación de la Universidad Pedagógica Nacional. Especialista en Currículo y Pedagogía de la Universidad de los Andes.

Correo Electrónico: kikeupn@gmail.com - jorge.ramirezm@usantotomas.edu.co

ORCID: https://orcid.org/0000-0002-1171-9710

Google Scholar: https://scholar.google.es/citations?user=AJenaYYAAAAJ\&hl=es 
en los sujetos educativos, pero alejada del disciplinamiento para no caer en la barbarie.

Palabras clave: cambio, civilidad, desencantamiento, escuela, socialización, posmodernidad.

\section{The disenchantment of the School: changes and upheaval in the post-industrial era}

\section{Abstract}

This article reflects on the upheaval and changes in the school in the post-industrial era through two perspectives: 1) the disenchantment of the school and its deinstitutionalization, and 2) civility: a conquest through the structure of socialization. Given the chaoticity, deinstitutionalization and widespread dispersion of the school as well as the subjectivity of the postmodern era, the study proposes a dialogue between some structures of the past and the present so that the loss of identity is not so rapid and does not lead to the loss of meaning of the world and of life. It is also proposes a new approach to the social structure of the school to form civility in educational subjects, other than a discipline based approach.

Keywords: change, civility, disenchantment, school, socialization, postmodernity.

\section{Introducción}

Cuando Arendt (1996) afirmó: "La educación es una de las actividades más elementales y necesarias de la sociedad humana, [...] la educación es el punto en el que decidimos si amamos al mundo lo 
bastante para asumir responsabilidad por él" (p. 197), hacía énfasis en la importancia que tiene la educación como dispositivo de socialización de la humanidad. Esta cita también permite comprender la responsabilidad mayor que tienen los maestros como hacedores de la educación y de la cultura, tal como lo han señalado Mockus (1984), Mosquera (2015a), Mosquera y Rodríguez (2018a) y Mosquera y Burgos (2017), al indicar que el maestro, como sujeto pedagógico, construye cultura y humaniza desde su labor.

Esta responsabilidad por la educación en perspectiva de un mundo mejor, de un sujeto socializado, es la que mueve al maestro a trabajar en medio de la dispersión generalizada de la que hablan Duch (2004), Beck (2002), Luhmann (1997), Giddens, Scott y Beck, (1997), al observar los cambios que ha experimentado la sociedad, al pasar de la época moderna o industrial a la posmoderna o posindustrial. Por eso sostiene Arendt (1996): "La crisis general que se apoderó del mundo moderno en su totalidad y en casi todas las esferas de la vida se manifiesta de distinto modo en cada país, se extiende por distintos campos y adopta distintas formas" (p. 185).

Son esos cambios los que han hecho que la sociedad actual sea dispersa y compleja. Esa dispersión y complejidad zarandean las instituciones sociales como la Escuela y producen la crisis, que según Altopiedi (2013) es de doble nivel en el ambito educativo: del sistema escolar en general y de cada establecimiento educativo en particular, ya que "la gran narrativa de que la escuela está en crisis, está ampliamente extendida en los discursos sobre esta institución" (p. 107).

En este contexto de crisis y dispersión generalizada, el presente manuscrito - que surge de nuestras experiencias como maestros- pretende reflexionar sobre los cambios e interrogantes que se le hacen a la Escuela, como pretexto para proponer un diálogo entre algunas estructuras del pasado y el presente, a través de las siguientes categorías: 1) el desencantamiento de la Escuela y su desinstitucionalización; 2) la civilidad: una conquista a través de la estructura de la socialización. De este modo, se piensa formar la civilidad en los alumnos, alejada de la visión disciplinaria ortodoxa 
de la educación, con el fin de que los procesos pedagógicos y las prácticas de los maestros no caigan en la barbarie, cuando se privilegia la exclusión y el éxito académico por encima de la estructura de acogida.

\section{El desencantamiento de la Escuela y su desinstitucionalización}

Al hablar del desencatamiento de la Escuela, se hace referencia a la crisis que la atraviesa, ya que dicha crisis es la que ha producido que los sujetos pierdan confianza ${ }^{3}$ en ella, y no la vean como una institución referente, como lo era en el pasado. La pérdida de visión de la Escuela como referente para la formación del sujeto y la construción de la sociedad anhelada es señal del caos presente que se vive en casi todas las instituciones sociales, producto de la secularización generalizada.

Que en la escuela se consuma sustancias psicoactivas; que el ambiente escolar se vuelva hostil por el bullying; que se presenten acontecimientos de violaciones y de acoso sexual entre los sujetos educativos; que haya un clivaje en las relaciones docente-padre de familia y alumnos, que la Escuela no seduzca al alumno con la narrativa de progreso a través de ella; que la sala de profesores no sea un espacio para la reflexión pedagógica, sino un lugar para venta de revistas, pintarse las uñas, asesorías para créditos bancarios, etc.; que la Escuela tenga una imagen negativa ante un amplio imaginario social por lo que acontece en su interior, todas estas realidades son realidades tangibles de la secularización a la que ha llegado esta institución.

Se recuerda que la escuela en la era premoderna era un lugar sagrado, regida según Taylor (2014), por concepciones trascendentes y fuerzas morales. Pero como se ve, esa época se ha desvaneci-

3. Charles Taylor (2014), en su obra intitulada La era secular, profundiza sobre los cambios que ha experimentado la sociedad moderna, en la que el hombre se ha alejado de la plenitud (Dios), producto de la secularización vigente, que ha generado una negación o sustracción de lo sagrado, dando paso a un nuevo sujeto $y$, con ello, a una nueva sociedad. 
do, convirtiéndose en un mundo desencantado, que produce una sustración de la plenitud, de la trascendencia y de la moral. Quizás, esto es lo que ha llevado a que Duch (1997) sostenga que parte de la crisis del momento se debe al olvido que ha tenido la estructura de la cotrascendencia; es decir, el hombre se ha sustraido del mundo de lo sagrado. Al sustraerse el sujeto educativo del mundo encantado, indubitablemente la escuela se seculariza más; por tal razón, Noro (2012), Mosquera (2015b), Mosquera, Rondón y Tique (2016) han sostenido que la Escuela ha sido profanada, en vista de los fenómenos que se dan en su interior y los cambios que padece de forma continua.

Cabe aclarar que, con esta línea argumentativa, no estamos haciendo una apología ciega de la fe, sino analizar el porqué se han dado algunos cambios o mutaciones en la Escuela y ver la crisis que presenta. Esto también permite explicar el por qué no puede seguir cumpliendo su función con lujos y detalles, como lo hacía otrora en la época premoderna y hasta avanzada la modernidad, y el por qué aparecen tantos cuestionamientos hacia su actual estado, ya que "los cambios de época suelen ir acompañados por un cuestionamiento y rediseño de la red institucional que articulan y sostiene el orden" (Tiramonti, 2004, p. 101). En tal sentido, tiene razón Altopiedi (2013) cuando afirma lo siguiente:

En términos muy generales, la institución educativa tiende a verse globalmente cuestionada, tanto por discursos postmodernos que objetan la universabilidad de su valor, como por aquellos que la acusan de faltar a las expectativas que la modernidad depositase en ella. (p. 108)

Muchos de estos cuestionamientos fuertes y fatalistas son el reflejo de la desinstitucionalización de la Escuela, pues anuncian la idea, según Tiramonti (2004), de que la escuela cayó. Surgen, pues, ideas y cuestionamientos como "la Escuela ya no sirve", "la Escuela es obsoleta", "los maestros ya no enseñan nada", "¿qué es lo que la Escuela enseña que los jóvenes son groseros y contestatarios?", "¿qué es lo que aprenden los estudiantes para sus vidas porque andan en pandilas o militando en la delicuencia, en la drogadición, 
en la prostitución?", "esos muchachos están mal formados porque no saben leer ni escribir bien". Recientemente, además, ha surgido la narrativa gubernamental, que la cuestiona porque no obtiene altos puntajes en pruebas externas, entre otros.

Si bien muchos de estos cuestionamientos no están totalmente desfasados de la realidad (muestran el desencantamiento y desinstitucionalización de la Escuela), según la perspectiva de donde se mire, la situación de fondo estriba en que se quiere y se espera que la Escuela sea esa institución sólida como lo fue en otro momento. Esta esperanza, por supuesto, es loable, pero a veces se olvida que, al estar inmersa en la sociedad posindustrial, dispersa, compleja y líquida —como dice Bauman (2007a, 2017b, 2013)—, la Escuela no puede estar atada a sólidos. Retomado a Bibian (2015), existe un proceso de licuefacción permanente que no permite que cuajen los fundamentos sólidos que caracterizaban a las instituciones premodernas y modernas, y que este proceso de licuefacción surge en su momento para derretir los sólidos de las tradiciones estancadas y aburguesadas, que no permitían movilidad ni cambio social, con la finalidad de crear un nuevo orden, un nuevo sólido; para ello, había que profanar lo sagrado, pero "la licuefacción se extendió y profundizó, y lejos de llegar a crear nuevos sólidos, las estructuras sociales derretidas se mantienen líquidas aún" (Bibian, 2015, p. 23).

El proceso de licuefacción no permite sólidos, pues hace que las instituciones pierdan sentido para los actores sociales, sobre todo en la tarea cómo se orienta la organización escolar (Altopiedi, 2013). De ahí que un amplio imaginario social piense que la Escuela no sirve, dado que se queda corta en el desempeño de las responsabildades asignadas; también piensan que la Escuela y la familia ya no educan con eficacia, porque no se ejerce una disciplina marcada.

Con Deleuze (2006) se sabe que se ha pasado de la sociedad disciplinaria a la de control, por lo que se comprueba que es imposible pensar en una educación sólida, entendida en términos de disciplinamiento. Por otra parte, están quienes quieren un cambio, un vuelco total de la Escuela conforme a los fenómenos de la pos- 
modernidad (aceleración, cambio permanente), desconociendo algunos aspectos significativos de la tradición, que servían como referencia ${ }^{4}$ para adquir un sentido de ser y estar en el mundo. Es decir, pareciera que existe un afán por acelerar el proceso de licuefacción de algunas estrucuras que se resisten a convertirse en líquidos, a ser derretidas con facilidad.

Creeríamos que, frente a las posturas modernas y posmodernas, debe existir un diálogo de estructuras en perspectiva provisional —si se nos permite la expresión- para no perder todas las referencias: algunas que fija la modernidad y otras que derrite la posmodernidad, para que el golpe del caos no se sienta tan fuerte.

La propuesta se hace porque, por una parte, "nuestro pasado está sedimentado en nuestro presente" (Taylor, 2014, p. 61), y porque, según Arendt (1996), la educación debe conservar aspectos de la tradición; por otra, no es bueno tener un sujeto sin referencias, aunque se sabe que, en escenarios de dispersión generalizada o de contingencias, no hay referencia fija, ya que "en la contingencia no puede expresarse nada que sea concluyente, irrefutable" (Duch, 1997). Según el mismo Duch (1997), "[...] ahora todos los puntos de referencia tradicionales se muestran por igual débiles" (p. 13), lo que desde la perspectiva de Giddens (1997a) profundiza aún más la crisis, ya que, al cambiar el sujeto las referencias con que se sujetaba en la modernidad por una autorrefencia que él mismo construye en la era posindutrial producto del desencaje epocal, produce que el mundo se vea como desbocado (Giddens, 1997b). Este desbocamiento para Tiramonti (2004) refleja las mutaciones o cambios que tienen las estructuras que sujetan a las personas, además de desorganizar el mundo en el que se mueven las instituciones y los mismos sujetos.

Precisamente por tal situación, es necesario un diálogo de referencias, que es lo mismo a un diálogo entre el pasado y el presente, ya que un sujeto sin referencias fácilmente puede extraviarse de camino. Beck (2002) habla de crear una segunda o nueva mo- 
dernidad, que no es posmodernidad, dado que la era posindustrial ha socavado los fundamentos de la primera modernidad, al transformar sus marcos de referencia.

La tesis de este manuscrito estriba en que se debe establecer un puente (recreación) entre algunas estructuras de la modernidad con la de la posmodernidad. Si se quiere una nueva modernidad para retomar a Beck (2002), es necesario reconocer la importancia de algunas estructuras de la tradición - que no es tradicionalismo-, con la finalidad de que el sujeto pueda conducirse en medio de la contingencia generalizada con cierto grado transitorio de coherencia (Duch, 2004). También es necesario que se recreen algunas de estas estructuras para que la desbocada del sujeto o de las instituciones no sea tan fuerte, al quedar sometidas al azar del caos y sin referencias, ya que ello innegablemente genera la pérdida de sentido sobre el mundo y la existencia.

En tal sentido, este puente se puede hacer teniendo en cuenta las tres estructuras que argumenta Duch (1997): codescendencia (familiar), corresidencia (polis como sociedad) y cotrascendencia (religarse a lo sagrado), como puntos de referencias, así sea de manera duraderamente transitoria.

También es fundamental que la escuela retome la estructura de su labor social, en términos de acogida, ya que dados los zarandeos que experimenta muchas veces se eclipsa siguiendo el relato de la exclusión para una amplia mayoría de alumnos, al cabalgar en concepciones de eficiencia y eficacia en el campo de la gestión escolar o administración educativa.

Tiene razón Bibian (2015) cuando sostiene que se debe evitar la tentación de la eficacia en la Escuela, pues ello agrava la visión de la institución debilitada. Una escuela que retome la estructura de la labor social es una escuela que — para citar a Meireiu (2013)_ acompaña a los alumnos en los éxitos y los fracasos.

En este orden de ideas, para establecer el puente entre algunas estructuras de la modernidad y la posmodernidad, los procesos 
pedagógicos no pueden caer en el afán de la moda (aceleración) hasta el punto de desreligarse de la tradición. Se cree, por el contario, que se debe recrear la tradición, lo que permite que el sujeto no pierda las referencias que lo han sujetado. La autorreferencia que desvincula la subjetividad de algunas estructuras del pasado no es la solución al caos, ya que se sabe que parte de la crisis actual se debe, según Duch (1997), al hundimiento de algunas estructuras que facilitan la transmisión del pasado.

\section{La civilidad: una conquista a través de la estructura de la socialización}

Se sabe que el ejercicio de educar no es fácil por muchos factores. Uno de ellos nos llama la atención: la vulnerabilidad que muestra la filosofía de la finitud del sujeto, que argumentan Levinas (2002), Mélich (2010, 1997, 2008), Mosquera y Rodríguez (2018b); inclusive, también lo ha referido Duch (2004), desde el campo de la antropología, cuando reflexiona sobre la finitud y la contingencia del sujeto.

Esta finitud y contingencia, que son connaturales al sujeto, motivan a Duch (2004), Levinas (2002) y Mélich (2010) para afirmar que el hombre es excéntrico; es decir, no tiene centro fijo de acción, es escurridozo. Al no tener un centro fijo, es un ser inacabado, impredescible. Por tal motivo, Morin (2003) sostiene lo siguiente:

El hombre es racional (sapiens), loco (demens), productor, técnico, constructor, ansioso, gozador, exótico, cantante, danzante, destructor, consciente, inconsciente, imaginante, inestable, fantasmante, neurótico, erótico, mágico, religioso. Todos estos rasgos se componen, se dispersan, se recomponen según los individuos, las sociedades, los momentos, aumentando la diversidad increíble de la humanidad... Pero todos estos rasgos salen a la luz a partir de las potencialidades del hombre genérico, ser complejo que reúne en sí contradicciones. (p. 71) 
Lo interesante es que tal complejidad y finitud del sujeto también ha sido analizada desde el lenguaje poético. Por ejemplo, el poeta antioqueño Porfirio Barba Jacob lo expresa así en su poema titulado Canción de la vida profunda:

Hay días en que somos tan móviles, tan móviles, como las leves briznas al viento y al azar.

Tal vez bajo otro cielo la Gloria nos sonríe.

La vida es clara, undívaga, y abierta como un mar.

$Y$ hay días en que somos tan fértiles, tan fértiles, como en abril el campo, que tiembla de pasión: bajo el influjo próvido de espirituales lluvias, el alma está brotando florestas de ilusión. Y hay días en que somos tan sórdidos, tan sórdidos, como la entraña obscura de oscuro pedernal: la noche nos sorprende, con sus profusas lámparas, en rútiles monedas tasando el Bien y el Mal.

Y hay días en que somos tan plácidos, tan plácidos... (¡niñez en el crepúsculo! ¡Lagunas de zafir!) que un verso, un trino, un monte, un pájaro que cruza, y hasta las propias penas nos hacen sonreír. $Y$ hay días en que somos tan lúbricos, tan lúbricos, que nos depara en vano su carne la mujer: tras de ceñir un talle y acariciar un seno, la redondez de un fruto nos vuelve a estremecer. $Y$ hay días en que somos tan lúgubres, tan lúgubres, como en las noches lúgubres el llanto del pinar. El alma gime entonces bajo el dolor del mundo, y acaso ni Dios mismo nos puede consolar. Mas hay también ¡Oh Tierra! un día... un día... un día... en que levamos anclas para jamás volver... Un día en que discurren vientos ineluctables ¡un día en que ya nadie nos puede retener!

Se insiste en la tarea fundante de comprender la condición finita, compleja y contingente de la subjetividad que se educa, porque 
se defiende la idea que la Escuela no puede perderlo de vista. Para que ella cumpla su misión civilizadora, no puede perder el horizonte de su estructura socializadora. Si la estructura socializadora se derrite, entra en un proceso de licuefación acelerado y pierde el sentido de lo humano, dando da paso a la barbarie.

Si una determinada escuela, por asegurar el rigor de la disciplina o el éxito académico, práctica la exclusión, le da paso a la barbarie, ya que la exclusión se camufla en el rechazo, la humillación y el sufrimiento para quienes lo padecen: sujetos finitos, que son muchas veces los estudiantes menos desfavorecidos, dado el entorno social y familiar en que están enquistados.

La Escuela no puede perder su estructura humanizadora. Es el buen trato y las buenas prácticas pedagógicas en los procesos educativos las que permiten la humanización de la subjetividad. En tal sentido, son válidas las palabras de Mèlich y Boixader (2010) cuando afirman que el acto educativo es ágape (amor); es este acto de amor el que posibilita retroceder la barbarie en la Escuela, cuando se privilegia el buen trato en las interrelaciones. Al respecto, sostiene Todorov (2008) que no tratar a los demás como humanos es una forma de barbarie.

Hay que tener mucho cuidado con el disciplinamiento excesivo en la Escuela en aras de cumplir con la misión civilizadora de la subjetividad, dado que las sanciones que afectan los derechos y la dignidad pueden entrar en la categoría de barbarie. No creemos que el disciplinamiento sea un método efectivo para controlar la fugacidad, la complejidad y la inestabilidad del alumno. En esto, la neurociencia tiene mucho que aportar desde el punto de vista del estudio del cerebro humano, dado que permite comprender actitudes comportamentales de la subjetividad.

Taylor (2014) describe cómo se conseguía la civilidad en la era premoderna y a comienzos de la modernidad fundamentada en la disciplina, en tanto se creía que la civilidad del sujeto se alcanzaba cuando se domesticaba lo salvaje de la persona, al afirmar lo siguiente: "Una imagen fundamental era la de la civilidad como 
resultado de haber disciplinado o domesticado una naturaleza originalmente salvaje, primitiva" (p. 168).

Ahora bien, esta civilidad pensada desde el disciplinamiento se daba así, según Taylor (2014), porque el Estado en su época deseaba una población saludable y disciplinada para fomar buenos soldados, personas sobrias y ordenadas, que tuvieran autocontrol racional y emocional, y fueran industriosos para tener un alto nivel de productividad. Resulta que, aunque todos estos ideales - que básicamente fueron los ideales de la Ilustración- no son malos, no pueden pensarse en clave de disciplinamiento en la Escuela posmoderna, porque la subjetividad que se educa en la escuela actualmente es diferente a la de entonces.

No debe perderse de vista la existencia evidente de la crisis generalizada en todas las instituciones del Estado, producto de los cambios de la sociedad posindustrial. Estos cambios hacen que los sujetos se vuelvan más complejos y dispersos, lo que implica indudablemente pensar los procesos educativos, los procesos de socialización y los procesos de civilidad de la subjetividad con nuevas estrategias pedagógicas y didácticas de manera serpentiante, modular, o buscándole la "comba al palo", como dice Mosquera (2015c), para conducir la enseñanza y el aprendizaje en medio de la complejidad y el caos de nuestros días.

Por eso se sostiene que la herramienta válida para formar una subjetividad civilizada no es el disciplinamiento ortodoxo, sino mediante el fortalecimiento de la estructura socializadora de la Escuela, pues es esta estructura la que acoge tanto al estudiante tranquilo como aquel que presenta rasgos de hiperactividad y dispersión, entre otros, ya que ese sujeto educativo se encuentra en proceso de transformación, en proceso de humanización (Arendt, 1996).

La exclusión hace que el sujeto se sustraiga de los códigos morales. Todorov (2008) afirma que los códigos que comportan la tradición humanizan las personas, y que civilizado es aquel que llega a conocer los códigos y las tradiciones, ya que ese conocimiento le permite entender los estados subjetivos de los otros y el funcionamiento de la sociedad. 
A veces se le exige al sujeto -en este caso, al sujeto modernoque respete y conserve la tradición. Pero si el sujeto se sustrae o se le sustrae de ese conocimiento porque ha sido excluido por el disciplinamiento, ¿cómo puede conocerla? La posibilidad para que la conserve y la respete depende de que la conozca, dado que conociendo algunas estructuras de la tradición - que no es tradicionalismo - es que voluntariamente se compromete a respetarla o recrearla. Este respeto por la tradición permite que el proceso de licuefación de algunas estructuras o códigos sea lento. Creemos que en esa licuefacción lenta es donde se pueden establecer puentes transitorios entre algunas estructuras del pasado y del presente, porque en el fondo "la idea de la civiliación implica, desde luego, el conocimiento del pasado. El que se sustraiga de la compresión del pasado e ignore los códigos comunes se condena a caer en la barbarie" (Todorov, 2008, p. 20).

\section{Conclusiones}

La crisis que evidencia la Escuela por los fenómenos que la invaden y los interrogantes que un sector significativo del imaginario social le hacen en diversas partes del mundo, debe convertirse en la oportunidad para repensar los procesos educativos de manera diferente (Arendt, 1996). Una forma diferente para pensar los procesos educativos que forman la civilidad del sujeto en la Escuela puede ser mediante la creación de un puente o diálogo entre algunas estructuras del pasado y el presente (en términos de recreación provisional), para que el sujeto no se quede sin referencias en un mundo posindutrial que cambia constantemente y zarandea los valores y las instituciones sociales, como la Escuela que fijó el ideal de la llustración en la Modernidad.

De igual modo, se hace necesario que la Escuela retome en sus procesos de enseñanza y aprendizaje la estructura social de acogida para sus usuarios, para evitar, de este modo, la exclusión social , y mejor, los acompañe tanto en el éxito como en el fracaso. 


\section{Referencias bibliográficas}

Altopiedi, M. (2013). El cambio y la crisis en la escuela. Una aproximación narrativa. Buenos Aires: Alternativa Pedagógica.

Arendt, H. (1996). Entre el pasado y el futuro Hannah Arendt. Ocho ejercicios sobrela reflexión política. Barcelona: Ediciones Península.

Bauman, Z. (2007a). Tiempos líquidos. Vivir en epocas de la incertidumbre. Buenos Aires: Tusquets.

Bauman, Z. (2007b). Los retos de la educación en la modernidad líquida. Barcelona: Gediza.

Bauman, Z. (2013). La cultura en el mundo de la modernidad líquida. Buenos Aires: Fondo de Cultura Económica.

Beck, U. (2002). La sociedad del riesgo. Hacia una nueva modernidad. Barcelona: Paidós

Bibian, D. (2015). Gestionar una escuela secundaria posible. Orientación escolar, asesoría pedagógica y función tutorial institucional. Buenos Aires: Noveduc.

Cogollo, C. (2014). Trayectorias de la sistematización de experiencias. Su constitución como posibilidad de pensar la producción de conocimiento en escenarios académicos. Revista Interamericana de Investigación, Educación y Pedagogía, RIIEP, 7(1). DOI: https://doi. org/10.15332/25005421

Ferreyra, H. A. (2014) Mesas Socioeducativas para la Inclusión y la Igualdad. Un programa "De todos con todos". Una experiencia en construcción. Revista Interamericana de Investigación, Educación y Pedagogía, RIIEP, 7(2). DOI: https://doi.org/10.15332/25005421

Giddens A. (1997a). Consecuencias de la modernidad. Barcelona: Alianza. 
Giddens A. (1997b). Un mundo desbocado. Barcelona: Alianza.

Giddens, A., Scott, L., \& Beck, U. (1997). Modernización reflexiva: política, tradición y estética en el orden social moderno. Madrid: Alianza

Deleuze, G. (2006). Post-scriptum sobre las sociedades de control. Revista Polis, 13. Recuperado de http://journals.openedition.org/polis/5509

Duch, L. (1997). La educación y la crisis de la modernidad. Barcelona: Paidós

Duch, L. ( 2004). Estaciones del laberinto. Ensayos de Antropología. Barcelona. Herder

Levinas, E. (2002). Totalidad e infinito. Ensayo sobre la exterioridad. Salamanca: Sígueme.

Luhmann, N. (1997). Observaciones de la modernidad. Racionalidad y contingencia en la sociedad moderna. Buenos Aires: paidós.

Mèlich, J. C. (2010a). El otro en sí mismo. Por una perspectiva desde el cuerpo. Barcelona: UOC

Mèlich, J. C., \& Boixader, A. (coord.). (2010). Los márgenes de la moral. Una mirada a la ética de la educación. Barcelona: Grao.

Mèlich, J. C. (1997). De lo extraño al cómplice: La educación en la vida cotidiana. Barcelona: Anthropos.

Mèlich, J. C. (2008). Antropología narrativa y educación. Teoría de le Educación, 20, 101-124.

Mockus, A. (1984). Movimiento pedagógico y defensa de la calidad de la educación pública. Educación y Cultura, 2, 27-34.

Mosquera, C. E. (2015a) Tres aportes del Movimiento Pedagógico Nacional, y una mirada a las Expediciones Pedagógicas como una nueva forma de hacer pedagogía. Educación y Cultura, 110, 68-71. Recuperado 
de http:// ipn.pedagogica.edu.co/ docs/ files/ REVISTA_110 \%20 educacion \%20y \%20cultura\%20-\%20FECODE.pdf

Mosquera, C. E. (2015b). Mi confesión, un texto y los estudiantes, otros textos: una oportunidad para reinventar la escuela. Revista Encuentro Educacional, 22(3), 447-459. Recuperado de http:// www.produccioncientificaluz.org/index.php/encuentro/article/ view/21228/21066

Mosquera, C. E. (2015c). Rumiar sobre el positivismo o transformar la práctica educativa pedagógica docente. Actualidades Pedagógicas, 65, 217-228. doi: http://doi.org/c89k

Mosquera, C., Rondón, I., \& Tique, J. (2016). Reinventar la escuela a partir de los textos de los actores escolares: maestros y estudiantes. Revista Praxis, 12(1), 21-29. Recuperado de doi: http://doi.org/c89m

Mosquera, C., \& Rodríguez, M. (2018a). Proyecto educativo como fundamento para pensar la subjetividad política desde la cultura escolar. El Ágora USB, 18(1), 255-267. doi: http://doi.org/c89n

Mosquera, C. E., \& Burgos, M. (2017). El Cliché de las competencias y la soberanía PISA. Revista Educación y Cultura, 118, 64-67.

Mosquera, C. E., \& Rodríguez, M. N. (2018b). El proyecto educativo institucional como fundamento para formar la subjetividad ética heterónoma. Praxis, 14(2).

Noro, J. E. (2012), La matriz de la escuela moderna: ¿escuela sagrada o escuela profana? Configuración, crisis y perspectivas. Tomo I: orígenes modernos. Madrid: Editorial Académica Española.

Pérez, T. H. P. (2013). Aproximaciones al estado de la cuestión de la investigación en educación y derechos humanos. Revista Interamericana de Investigación, Educación y Pedagogía, RIIEP, 6(1). DOI: https://doi. org/10.15332/s1657-107X.2013.0001.05 
Tiramonti, G. (Comp.) (2004). La trama de la desigualdad educativa. Mutaciones recientes en la escuela media. Buenos Aires: Manantial.

Taylor, C. (2014). La era secular. Barcelona: Gediza.

Todorov. T. (2008). El miedo a los bárbaros. Barcelona: Galaxi Gutenteberg. 